\title{
Obstructive Sleep Apnea as a Risk Factor for Type II Diabetes
}

\author{
Nader Botros, M.D., MPH ${ }^{1}$, John Concato, M.D. ${ }^{2,3}$, Vahid Mohsenin, M.D. ${ }^{1}$, Bernardo Selim, \\ M.D. ${ }^{1}$, Kervin Doctor, M.D. ${ }^{3}$, and Klar Yaggi, M.D., MPH ${ }^{1,3}$ \\ ${ }^{1}$ Division of Pulmonary, Critical Care, and Sleep Medicine, Yale University School of Medicine, New \\ Haven, CT \\ ${ }^{2}$ Division of General Internal Medicine, Yale University School of Medicine, New Haven, CT \\ ${ }^{3}$ Clinical Epidemiology Research Center (CERC), Veterans Affairs Connecticut Healthcare System, \\ West Haven, CT
}

\section{Abstract}

PURPOSE-Cross-sectional studies have documented the co-occurrence of obstructive sleep apnea (hereafter sleep apnea) with glucose intolerance, insulin resistance, and type II diabetes mellitus (hereafter diabetes). It has not been determined, however, whether sleep apnea is independently associated with the subsequent development of diabetes, accounting for established risk factors.

METHODS-This observational cohort study examined 1233 consecutive patients in the Veteran Affairs Connecticut Health Care System referred for evaluation of sleep-disordered breathing; 544 study participants were free of preexisting diabetes and completed a full, attended, diagnostic polysomnogram. The study population was divided into quartiles based on severity of sleep apnea as measured by the apnea-hypopnea index. The main outcome was incident diabetes defined as fasting glucose level $>126 \mathrm{mg} / \mathrm{dL}$ and a corresponding physician diagnosis. Compliance with positive airway pressure therapy, and its impact on the main outcome, was also examined.

RESULTS-In unadjusted analysis, increasing severity of sleep apnea was associated with an increased risk of diabetes ( $\mathrm{P}$ for linear trend $<0.001$ ). After adjusting for age, sex, race, baseline fasting blood glucose, body mass index (BMI), and weight change, an independent association was found between sleep apnea and incident diabetes (hazard ratio per quartile 1.43; CI 1.10-1.86). Among patients with more severe sleep apnea (upper two quartiles of severity), $60 \%$ had evidence of regular positive airway pressure use, and this treatment was associated with an attenuation of the risk of diabetes (log-rank test $\mathrm{P}=0.04$ ).

CONCLUSION-Sleep apnea increases the risk of developing diabetes, independent of other risk factors. Among patients with more severe sleep apnea, regular positive airway pressure use may attenuate this risk.

\section{Keywords}

Sleep Apnea Syndrome; Type 2 Diabetes Mellitus

\footnotetext{
Publisher's Disclaimer: This is a PDF file of an unedited manuscript that has been accepted for publication. As a service to our customers we are providing this early version of the manuscript. The manuscript will undergo copyediting, typesetting, and review of the resulting proof before it is published in its final citable form. Please note that during the production process errors may be discovered which could affect the content, and all legal disclaimers that apply to the journal pertain.

All authors had access to the data and a role in writing the manuscript. They have no relevant conflicts of interest to disclose.
} 


\section{INTRODUCTION}

The prevalence of type 2 diabetes continues to increase in the U.S. and currently affects an estimated 18 million people. ${ }^{1}$ Although lifestyle changes, such as weight loss and physical activity, are the cornerstone of diabetes prevention, efforts are needed to better understand other disease determinants and to develop additional strategies for prevention. Understanding the link between obstructive sleep apnea and diabetes may represent one such effort.

Obstructive sleep apnea (hereafter sleep apnea) is a common and treatable form of sleepdisordered breathing, involving upper airway collapse during sleep. This collapse results in a cycle of physiologic events that occur repeatedly throughout the night, including intermittent hypoxemia and arousal from sleep. Sleep apnea is present in $9-24 \%$ of the middle aged adult population ${ }^{2}$ and has been associated with increased rates of hypertension, atherosclerosis, cardiovascular morbidity and mortality (including stroke), and all-cause mortality.3-7

Recent short-term studies have demonstrated striking alterations in metabolic function, including glucose intolerance and insulin resistance, associated with short-term sleep restriction 8,9 and sleep apnea. ${ }^{8,10-15}$ These findings raise the question of whether sleep apnea may have a role in development of overt clinical diabetes. The current study evaluated longitudinally whether sleep apnea is an independent risk factor for diabetes. In addition, we explored whether positive airway pressure, as the main medical therapy for sleep apnea, had an impact on this risk.

\section{METHODS}

\section{Study Design and Patient Population}

This observational cohort study examined non-diabetic patients referred to the Veterans Affairs (VA) Connecticut Sleep Center from January 2000 to December 2005. Eligible participants include patients referred for initial evaluation of sleep-disordered breathing who had at least 2 hours of sleep monitoring and a fasting glucose level less than $126 \mathrm{mg} / \mathrm{dL}$. Participants were excluded if the entire polysomnographic study was performed with airway pressurization for therapeutic purposes. The study was approved by the institutional review board at the VA Connecticut Health Care System.

\section{Baseline Assessment}

Data on demographics, sleep and medical history, and medication use/habits were extracted from each patient's medical record. Hypertension occurred if the average blood pressure was $\geq 140 \mathrm{~mm} \mathrm{Hg}$ (systolic) or $\geq 90 \mathrm{~mm} \mathrm{Hg}$ (diastolic) from three office visits prior to polysomnography or if patients had a history of hypertension. Hyperlipidemia was based on history or an appropriate drug prescription. Baseline fasting blood glucose values (with all patients routinely tested) were obtained within three months of initial polysomnogram. Each patient's body mass index (BMI) was calculated at the time of polysomnogram and at follow up. The Epworth Sleepiness Scale, a measure of sleepiness, ${ }^{16}$ was also recorded.

\section{Polysomnography}

At baseline, participants underwent a full, attended, overnight polysomnography, with the use of Grass data-acquisition systems (Astro-Med ${ }^{\circledR}$ ). Recordings were manually scored according to standard criteria.17-19 Calculated variables included the arousal index (number of arousals/ hour of sleep), minimum arterial oxygen saturation, mean arterial oxygen saturation, T90\% (percentage of total sleep time with oxygen saturation less than 90\%), and the apnea hypopnea index (the sum of apneas and hypopneas/hour of sleep). The study population was divided into quartiles based on severity of sleep apnea as measured by the apnea hypopnea index. 


\section{Outcomes}

The primary outcome was the development of diabetes, measured from the interval of the initial polysomnogram to the date of first office visit in which the diagnosis of diabetes occurred. Diabetes was defined by a physician diagnosis during routine office visit and fasting blood glucose $>126 \mathrm{mg} / \mathrm{dL}^{20}$ (using Hexokinase/G-6-PDH methodology through the Architect/ Aeroset system, Abbott Laboratories, IL, USA). A physician investigator, unaware of patients' sleep apnea status, reviewed electronic medical records to ascertain incident diabetes.

Censoring occurred at end of follow up (last office visit prior to July 31, 2006), or the time of death (if death occurred).

\section{Positive Airway Pressure Treatment Compliance}

This VA study population received treatment according to consensus guidelines, ${ }^{21}$ and appliance and supplies were ordered by the institution and issued through a single respiratory home care company. Importantly, the orders for these services are documented in the electronic medical record. In addition, patients are followed closely for assessment of efficacy and treatment compliance through established sleep medicine and pulmonary clinics where positive airway pressure use is documented. Two physician-investigators, blinded to outcome status, categorized each patient's airway pressurization treatment use in categories of: 1) not ordered, 2) no use, 3) intermittent use, and 4) continuous or "regular" use of positive airway pressure. For the purposes of these analyses, airway pressurization compliance was dichotomized into "regular use" or not.

\section{Statistical Analysis}

Student's $t$-test was used to compare mean values at baseline between subjects in the first quartile (comparison group) with the upper three quartiles (sleep apnea group). Categorical data was compared using the chi-square test. A nonparametric comparison of medians was done with the Wilcoxon-Mann-Whitney test.

Kaplan-Meier analysis was used to compare event-free survival among patients with and without sleep apnea. An analysis using the chi-square test for linear trend was done to analyze whether increased severity of sleep apnea was associated with an increased risk of developing diabetes.

Subsequently, using proportional-hazards analysis, hazard ratios and 95\% confidence intervals were generated for the unadjusted association between sleep apnea and incident diabetes. Adjusted hazard ratios were then calculated to account for the confounding effects of other baseline characteristics, including, age, gender, race, BMI, change in BMI (over the follow up period), and baseline fasting glucose.

To examine the impact of positive airway pressure appliance use on diabetes, compliance (defined as percentage of patients with regular appliance use) was first examined by quartile of sleep apnea severity. Anticipating that regular use would be significantly higher among those with more severe sleep apnea, a pre-specified subgroup analysis sought to investigate the impact of regular positive airway pressure use on incident diabetes among the upper two quartiles of severity (quartiles 3 and 4). This association was examined first using KaplanMeier analysis, and subsequently in multivariable analysis using Cox proportional hazards analysis.

Based on an available sample size of 544 participants, $90 \%$ power existed to detect a hazard ratio (HR) of 1.38 for two-sided alpha at the 0.05 level $^{22}$ for the primary outcome of diabetes. All statistical tests were performed with the use of SAS software, with the exception of the Kaplan-Meier curves, for which S-Plus software was used. 


\section{RESULTS}

Between January 2000 and July 2005, 1233 consecutive patients were referred to the VA Connecticut Sleep Center; 407 (33\%) patients were ineligible because there were referred for conditions other than sleep-disordered breathing, or they had no initial diagnostic study. An additional 233 (19\%) patients were ineligible because they had previously diagnosed diabetes, and $49(4 \%)$ patients were excluded because they had incomplete polysomnographic data. Data for the remaining 544 patients were included in the study.

Table 1 shows the baseline characteristics of participants according to quartile of severity of the apnea-hypopnea index. The mean apnea hypopnea index in the sleep apnea group was 41.5 , compared to 2.9 in the comparison group. The baseline fasting blood glucose values were higher in the sleep apnea group compared to the comparison group ( $99.4 \mathrm{mg} / \mathrm{dL}$ vs. $95.3 \mathrm{mg} /$ $\mathrm{dL}$, respectively; $\mathrm{P}=0.05$ ). As expected, the prevalence of obesity (defined as $\mathrm{BMI}>30$ ) was higher in the sleep apnea group, as was the prevalence of hypertension. The sleep apnea group was also older, with a mean age of 62.9 years vs. 57.6 years, respectively. Obstructive apneas were the predominant apneic event; central apneas were rare.

Follow-up after the index sleep study took place between January 1, 2005 and July 31, 2006. Patients in groups with or without sleep apnea had a mean duration of follow up of 2.7 years from baseline. Incident diabetes occurred in 61 patients, with 55 events occurring in the sleep apnea group compared with 6 events in the comparison group (5.5 vs. 1.8 events per 100 person years, respectively). Figure 1 shows the Kaplan-Meier (unadjusted) estimates of time to the endpoint of diabetes; the probability of developing diabetes was significantly higher for the sleep apnea group than for the comparison group ( $\log$ rank test, $\mathrm{P}=0.002)$.

An initial analysis of linear trend revealed an increased risk of incident diabetes as a function of an increased severity of sleep apnea ( $\mathrm{P}<0.001$; data not shown). In unadjusted analysis (Table 2), a significant association was found between sleep apnea (categorized by quartiles with increasing severity) and incident diabetes (HR per quartile 1.53; 95\% CI 1.21-1.94; $\mathrm{P}=0.0005)$. In particular, the unadjusted risk of incident diabetes for subjects in the fourth quartile of severity was more than four and a half times that in the comparison group (HR 4.67; 95\% CI $1.92-11.34 ; \mathrm{p}=0.0007)$.

After adjusting for age, gender, race, baseline fasting blood glucose, BMI, and change in BMI, sleep apnea retained a statistically significant association with diabetes (adjusted HR per quartile $1.43 ; 95 \%$ CI 1.10-1.86; $\mathrm{P}=0.008$ ); see Table 2. The association of both fasting blood glucose and change in BMI with incident diabetes persisted after adjustment. In a secondary, explanatory analysis, both T90 (as measures of hypoxia) and arousal index also had statistically significant hazard ratios for their association with diabetes; data not shown.

Regular use of positive airway pressure was observed in $28 \%$ of patients in the second quartile, and no significant impact of this use was observed. Regular use increased to 58\% and $62 \%$ in the third and fourth quartiles, respectively, and Figure 2 shows the Kaplan-Meier estimates of the time to incident diabetes in this subgroup. The probability of incident diabetes was attenuated for those with regular positive airway pressure use compared to those without (logrank test, $\mathrm{P}=0.04$ ). In adjusted analyses among these same participants, regular use of positive airway pressure was independently associated with a significantly attenuated risk of incident diabetes (HR 0.53; 95\% CI 0.28-0.99; $\mathrm{P}=0.04$ ), even after adjusting for baseline fasting blood glucose, BMI, and change in BMI at follow-up. 


\section{COMMENTS}

We conducted an observational cohort study examining the impact of sleep apnea on the development of type II diabetes mellitus. Our results show that a) sleep apnea is a risk factor for the development of diabetes; b) increasing severity of sleep apnea is associated with an increasing risk for the development of diabetes; and, c) among patients with moderate to severe sleep apnea (upper 2 quartiles of severity), regular use of positive airway pressure is associated with an attenuated risk for the development of incident diabetes.

Our findings are consistent with previous cross-sectional data showing an association between sleep apnea and insulin resistance, glucose intolerance, and diabetes. ${ }^{8}, 11,13,14,23-25$ The causal direction of these associations, however, has been questioned. ${ }^{26-28}$ The few studies assessing longitudinal associations between sleep apnea and diabetes have had limitations. For example, sleep apnea was associated with development of diabetes during a 10-year followup period, but sleep apnea was determined by a self-report of snoring as a surrogate for a confirmed diagnosis. ${ }^{29,}{ }^{30}$ In addition, a longitudinal analysis of the Wisconsin Cohort found an association between sleep apnea and diabetes, but the impact of sleep apnea was not statistically significant when adjusted for BMI. ${ }^{24}$ Finally, a recent longitudinal analysis of the Busselton Health Study detected an association between moderate-severe sleep apnea and diabetes using portable monitoring, but the small sample size, limited distribution of sleep apnea severity, and few incident cases of diabetes resulted in a wide confidence interval. ${ }^{31}$ Our study is novel in that it used a longitudinal design that was powered to demonstrate an independent association between confirmed sleep apnea and diabetes, used the gold standard test for diagnosis, assessed a broad range of sleep apnea severity, and examined the impact of sleep apnea treatment.

Several potential mechanistic pathways may explain how sleep apnea and its physiologic sequelae (intermittent hypoxemia and recurrent arousals) ultimately lead to metabolic abnormalities. Previous studies found that severity of hypoxemia is related to the degree of glucose intolerance and insulin resiatnce. ${ }^{8}, 32,33$ Although insulin levels were not available in the current study, hypoxemia (T90, defined as a greater than $2 \%$ of the night spent with an oxygen saturation less than $90 \%$ ) was significantly associated with the outcome of diabetes (data not shown); intermittent hypoxemia may act through mechanisms of oxidative stress to mediate alterations in glucose metabolism. $34^{-} 35 \mathrm{We}$ also observed that the arousal index was associated with development of diabetes. Recurrent arousals (and sleep loss) may act through sympathetic activation and subsequent alterations in hypothalamic-pituitary-adrenal axis, leading to altered cortisol levels, decreased pancreatic beta-cell activity, elevated growth hormone levels, and alterations in neuroendocrine control of appetite. ${ }^{35-39}$

Our findings suggest an increased risk of diabetes among patients with sleep apnea, despite "usual care" administration of various therapies, primarily positive airway pressure. A few explanations might account for this finding. First, it is likely that our population had untreated sleep apnea for years before seeking diagnosis and treatment, resulting in prolonged exposure to an associated metabolic risk. Second, diabetes may develop even if patients receive effective therapy for sleep apnea. Finally, reduced compliance with positive airway pressure and limited efficacy of other treatments may have played a role in reducing the potential benefit of therapy.

We observed that regular use of positive airway pressure among patients in the upper two quartiles of severity was associated with a significant attenuation of incident diabetes, even after adjusting for subsequent weight loss. These findings are consistent with several treatment studies that have demonstrated improvements in insulin sensitivity and postprandial glucose with airway pressurization therapy. ${ }^{40-42}$ In contrast, others studies, including 2 short-term randomized controlled trials, have not shown a benefit.23, ${ }^{25}$ Future longitudinal and 
randomized studies examining the impact of treatment in various patient populations (e.g. sleepy and non-sleepy patients) are needed.

Several methodologic issues should be considered in the interpretation of our results. First, as with any observational study, it is possible that residual confounding affected our adjusted hazard ratios, despite our attempts to control for major risk factors. For example, family history of diabetes could not be reliably ascertained through electronic medical record extraction and was not included in our analysis. In addition, BMI may not fully adjust for visceral obesity, known to be associated with components of the metabolic syndrome. ${ }^{47,48}$ Our comparison group also consisted of mainly obese males referred for suspected sleep apnea, however, thereby reducing the potential for residual confounding, given that similar risk factors were prominent in the comparison group. Change in BMI was also accounted for, to exclude the possibility that differential weight gain in one group may account for the difference in incident diabetes during the study.

Second, tracking of positive airway pressure treatment status was done through documentation in the electronic record, based on clinical assessment by treating physicians in conjunction with documentation of equipment and supply orders. Although the possibility of misclassification of treatment status exists (with a bias towards the null hypothesis), this scenario would not explain our observed findings of the attenuation of incident diabetes conferred by positive airway pressure use among our patients in the upper 2 quartiles of sleep apnea severity. In addition, our moderate long-term rates $(\sim 60 \%)$ of regular CPAP use are similar to those described using direct data card measures that track hours of use. ${ }^{43}$

Third, treatment status in this observational cohort study was not randomly assigned. Patients who complied with positive airway pressure may have also been leading healthier lifestyles and complying with other therapies for the prevention of diabetes (e.g., diet and exercise). Yet, this possibility would not explain the attenuation of incident diabetes among patients in the upper 2 quartiles of severity that was observed even after adjustment for weight loss.

Finally, the relatively low observed values for the Epworth Sleepiness Scale (mean <9; see Table 1) may prompt questions regarding thresholds for initiating CPAP in the context of risk of future diabetes. Virtually all patients in our study were symptomatic, however, with episodes such as gasping during sleep, loud habitual snoring, or a bed-partner noting witnessed apneas; many of these patients also had coexistent cardiovascular risk factors and some had prevalent cardiovascular disease. Thus, caution is warranted in extrapolating our findings to healthier populations.

In summary, sleep apnea is significantly associated with the risk of type II diabetes, independently of other risk factors, including age, race, gender, baseline fasting glucose, and BMI, and changes in BMI. Increased severity of sleep apnea is associated with an increased risk of diabetes, and the risk may be partially explained by hypoxemia and arousals. As a treatable condition, sleep apnea may represent a modifiable risk factor for development of diabetes.

\section{Acknowledgments}

Funding Sources: VA Health Services Research and Development/Clinical Science, Career Development Awards to Dr. Yaggi. National Research Service Award Institutional Research Training Grant (5T32HL07778) to Dr. Botros.

\section{CITATIONS}

1. Diagnosis and classification of diabetes mellitus. Diabetes Care Jan;2005 28(Suppl 1):S37-42. [PubMed: 15618111] 
2. Young T, Palta M, Dempsey J, Skatrud J, Weber S, Badr S. The occurrence of sleep-disordered breathing among middle-aged adults. N Engl J Med Apr 29;1993 328(17):1230-1235. [PubMed: 8464434]

3. Drager LF, Bortolotto LA, Figueiredo AC, Krieger EM, Lorenzi GF. Effects of continuous positive airway pressure on early signs of atherosclerosis in obstructive sleep apnea. Am J Respir Crit Care Med Oct 1;2007 176(7):706-712. [PubMed: 17556718]

4. Marin JM, Carrizo SJ, Vicente E, Agusti AG. Long-term cardiovascular outcomes in men with obstructive sleep apnoea-hypopnoea with or without treatment with continuous positive airway pressure: an observational study. Lancet Mar 19-25;2005 365(9464):1046-1053. [PubMed: 15781100]

5. Peppard P, Young T, Palta M, Skatrud JB. Prospective study of the association between sleepdisordered breathing and hypertension. NEJM 2000;342(19):1378-1384. [PubMed: 10805822]

6. Yaggi H, Concato J, Kernan W, Lichtman J, Brass L, Mohsenin V. Obstructive Sleep Apnea as a Risk Factor for Stroke and Death. NEJM 2005;353:2034-2041. [PubMed: 16282178]

7. Young T, Finn L, Peppard P, et al. Sleep DIsordered Breathing and Mortality: Eighteen-Year Followup of the Wisconsin Sleep Cohort. Sleep 2008;31(8):1071-1078. [PubMed: 18714778]

8. Punjabi NM, Shahar E, Redline S, Gottlieb DJ, Givelber R, Resnick HE. Sleep-disordered breathing, glucose intolerance, and insulin resistance: the Sleep Heart Health Study. Am J Epidemiol Sep 15;2004 160(6):521-530. [PubMed: 15353412]

9. Yaggi HK, Araujo AB, McKinlay JB. Sleep duration as a risk factor for the development of type 2 diabetes. Diabetes Care Mar;2006 29(3):657-661. [PubMed: 16505522]

10. Coughlin SR, Mawdsley L, Mugarza JA, Calverley PM, Wilding JP. Obstructive sleep apnoea is independently associated with an increased prevalence of metabolic syndrome. Eur Heart J May; 2004 25(9):735-741. [PubMed: 15120883]

11. Ip MS, Lam B, Ng MM, Lam WK, Tsang KW, Lam KS. Obstructive sleep apnea is independently associated with insulin resistance. Am J Respir Crit Care Med Mar 1;2002 165(5):670-676. [PubMed: 11874812]

12. Meslier N, Gagnadoux F, Giraud P, et al. Impaired glucose-insulin metabolism in males with obstructive sleep apnoea syndrome. Eur Respir J Jul;2003 22(1):156-160. [PubMed: 12882466]

13. Punjabi NM, Sorkin JD, Katzel LI, Goldberg AP, Schwartz AR, Smith PL. Sleep-disordered breathing and insulin resistance in middle-aged and overweight men. Am J Respir Crit Care Med Mar 1;2002 165(5):677-682. [PubMed: 11874813]

14. Resnick HE, Redline S, Shahar E, et al. Diabetes and sleep disturbances: findings from the Sleep Heart Health Study. Diabetes Care Mar;2003 26(3):702-709. [PubMed: 12610025]

15. Tiihonen M, Partinen M, Narvanen S. The severity of obstructive sleep apnoea is associated with insulin resistance. J Sleep Res Mar;1993 2(1):56-61. [PubMed: 10607072]

16. Johns MW. A new method for measuring daytime sleepiness: the Epworth Sleepiness Scale. Sleep 1991;14:540-545. [PubMed: 1798888]

17. Sleep-related breathing disorders in adults: recommendations for syndrome definition and measurement techniques in clinical research. The Report of an American Academy of Sleep Medicine Task Force. Sleep Aug 1;1999 22(5):667-689. [PubMed: 10450601]

18. Meoli AL, Casey KR, Clark RW, et al. Hypopnea in sleep-disordered breathing in adults. Sleep Jun 15;2001 24(4):469-470. [PubMed: 11403531]

19. Rechtschaffen, A.; Kales, A.; UCLA. A Manual of Standardized Terminology, Techniques and scoring System for Sleep Stages of Human Subjects. Brain Information Service/Brain Research Institute; Los Angeles: 1968.

20. ADA. Diagnosis and Classification of Diabetes Mellitus. Diabetes Care 2008;31(Supplement 1):s55s60. [PubMed: 18165338]

21. Loube DI, Gay PC, Strohl KP, Pack AI, White DP, Collop NA. Indications for positive airway pressure treatment of adult obstructive sleep apnea patients: a consensus statement. Chest 1999;115(3):863866. [PubMed: 10084504]

22. Schoenfeld P. Sample-size Formula for the Proportional-Hazards Regression Model. Biometrics June; 1983 39(2):499-503. 1983. [PubMed: 6354290] 
23. Coughlin SR, Mawdsley L, Mugarza JA, Wilding JP, Calverley PM. Cardiovascular and metabolic effects of CPAP in obese males with OSA. Eur Respir J Apr;2007 29(4):720-727. [PubMed: 17251237]

24. Reichmuth KJ, Austin D, Skatrud JB, Young T. Association of sleep apnea and type II diabetes: a population-based study. Am J Respir Crit Care Med Dec 15;2005 172(12):1590-1595. [PubMed: 16192452]

25. West SD, Nicoll DJ, Wallace TM, Matthews DR, Stradling JR. Effect of CPAP on insulin resistance and $\mathrm{HbA1c}$ in men with obstructive sleep apnoea and type 2 diabetes. Thorax Nov;2007 62(11):969974. [PubMed: 17557769]

26. West S. Prevalence of Obstructive Sleep Apnea in Men with Type 2 Diabetes. Thorax November; 2006 61(11):945-950. 2006. [PubMed: 16928713]

27. Ficker JH, Dertinger SH, Siegfried W, et al. Obstructive sleep apnoea and diabetes mellitus: the role of cardiovascular autonomic neuropathy. Eur Respir J Jan;1998 11(1):14-19. [PubMed: 9543264]

28. Bottini P. Sleep-Disordered Breathing in Nonobese diabetic subjects with Autonomic Neuropathy. Eur Respir J October;2003 22(4):654-660. 2003. [PubMed: 14582920]

29. Al-Delaimy WK, Manson JE, Willett WC, Stampfer MJ, Hu FB. Snoring as a risk factor for type II diabetes mellitus: a prospective study. Am J Epidemiol Mar 1;2002 155(5):387-393. [PubMed: 11867347]

30. Elmasry A, Janson C, Lindberg E, Gislason T, Tageldin MA, Boman G. The role of habitual snoring and obesity in the development of diabetes: a 10-year follow-up study in a male population. J Intern Med Jul;2000 248(1):13-20. [PubMed: 10947876]

31. Marshall NS, Wong KK, Phillips CL, Liu PY, Knuiman MW, Grunstein RR. Is sleep apnea an independent risk factor for prevalent and incident diabetes in the Busselton Health Study? J Clin Sleep Med Feb 15;2009 5(1):15-20. [PubMed: 19317376]

32. Redline S, Storfer-Isser A, Rosen CL, et al. Association between Metabolic Syndrome and Sleepdisordered Breathing in Adolescents. Am J Respir Crit Care Med Aug 15;2007 176(4):401-408. [PubMed: 17541017]

33. Sulit L, Storfer-Isser A, Kirchner HL, Redline S. Differences in polysomnography predictors for hypertension and impaired glucose tolerance. Sleep Jun 1;2006 29(6):777-783. [PubMed: 16796216]

34. Polotsky V. Intermittent Hypoxia Increases Insulin Resistance in Genetically Obese Mice. Journal of Physiology July 23;2003 (5521):253-264. 2003. [PubMed: 12878760]

35. Yamauchi M, Nakano H, Maekawa J, et al. Oxidative stress in obstructive sleep apnea. Chest May; 2005 127(5):1674-1679. [PubMed: 15888845]

36. Punjabi N. Disorders of Glucose Metabolism in Sleep Apnea. J Appl Physiol November;2005 99:1998-2007. 2005. [PubMed: 16227461]

37. Chasens ER, Weaver TE, Umlauf MG. Insulin resistance and obstructive sleep apnea: is increased sympathetic stimulation the link? Biol Res Nurs Oct;2003 5(2):87-96. [PubMed: 14531213]

38. Somers VK, Mark AL, Abboud FM. Sympathetic activation by hypoxia and hypercapnia-implications for sleep apnea. Clin Exp Hypertens A 1988;10(Suppl 1):413-422. [PubMed: 3072127]

39. Somers VK, Dyken ME, Clary MP, Abboud FM. Sympathetic neural mechanisms in obstructive sleep apnea. J Clin Invest Oct;1995 96(4):1897-1904. [PubMed: 7560081]

40. Babu AR, Herdegen J, Fogelfeld L, Shott S, Mazzone T. Type 2 diabetes, glycemic control, and continuous positive airway pressure in obstructive sleep apnea. Archives of Internal Medicine 2005;165(4):447-452. [PubMed: 15738376]

41. Harsch IA, Schahin SP, Bruckner K, et al. The effect of continuous positive airway pressure treatment on insulin sensitivity in patients with obstructive sleep apnoea syndrome and type 2 diabetes. Respiration May-Jun;2004 71(3):252-259. [PubMed: 15133345]

42. Harsch IA, Schahin SP, Radespiel-Troger M, et al. Continuous positive airway pressure treatment rapidly improves insulin sensitivity in patients with obstructive sleep apnea syndrome. Am J Respir Crit Care Med Jan 15;2004 169(2):156-162. [PubMed: 14512265]

43. Hirshkowitz, M.; Littner, M.; Kuna, S.; Berry, RB.; Norris, M.; Almenoff, P. Sleep-related Breathing Disorders: Sourcebook. Vol. 2nd Edition. Healthcare Analysis \& Information Group (HAIG), VHA; Milwaukee, WI: 2003. 


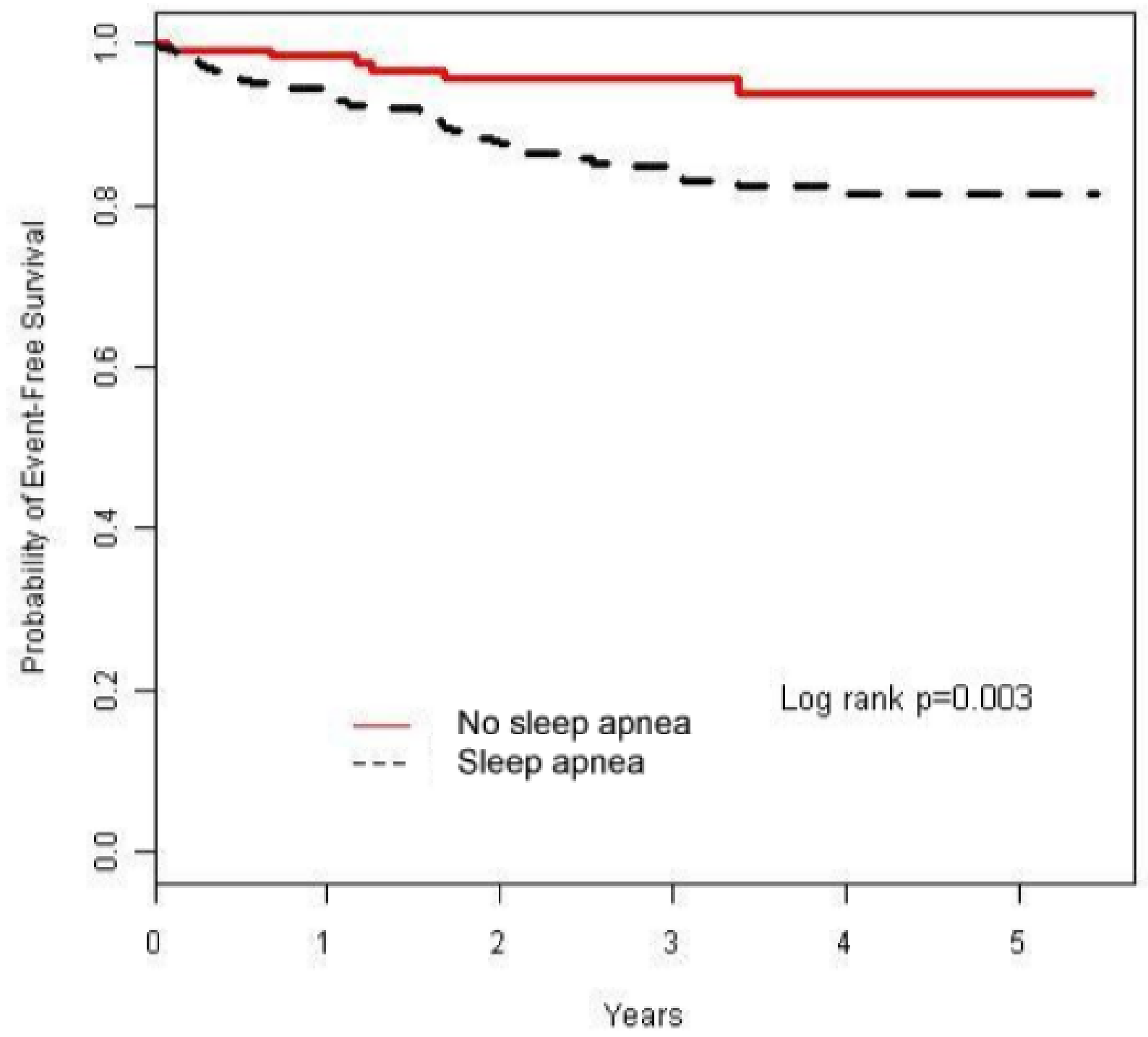

Figure 1.

Kaplan - Meier Curves for the association of sleep apnea and diabetes. Sleep apnea defined as apnea-hypopnea index $\geq 8$. 


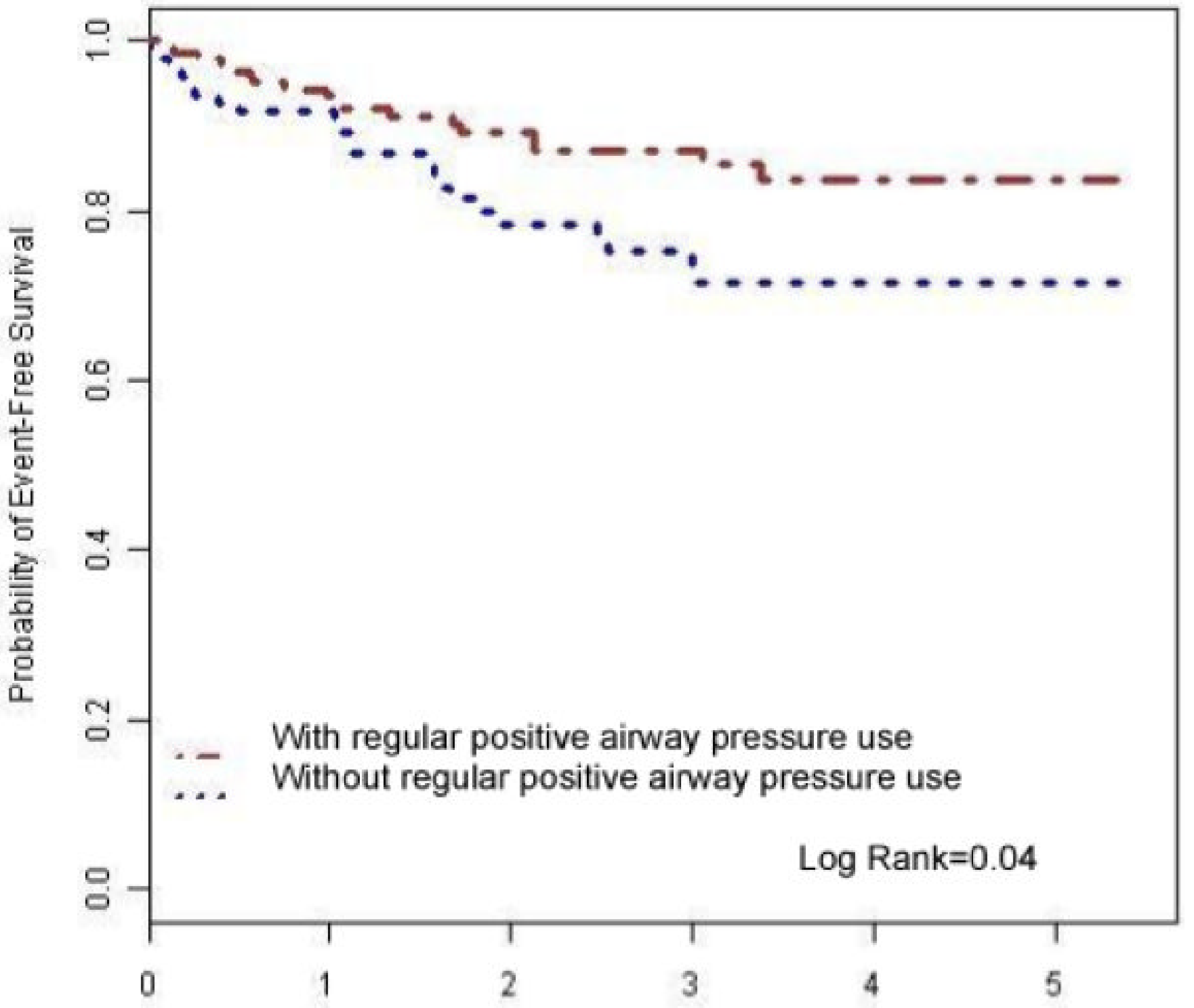

\section{Years}

Figure 2.

Kaplan - Meier Curves examining the impact of regular continuous positive airway pressure on the risk of incident diabetes among patients in the upper two quartiles of apnea hypopnea index severity (quartiles 3 and 4). 
Table 2

Unadjusted and adjusted hazard ratios for the risk of diabetes $(\mathrm{N}=544)$

\begin{tabular}{lll}
\hline Factor & $\begin{array}{l}\text { Unadjusted Hazard Ratio; } \\
\mathbf{( 9 5 \% ~ C I ; ~ P ~ v a l u e ~})\end{array}$ & $\begin{array}{l}\text { Adjusted Hazard Ratio; } \\
\mathbf{( 9 5 \% ~ C I} ; \mathbf{P} \text { value })\end{array}$ \\
Age & $0.99(0.98-1.02 ; \mathrm{P}=0.92)$ & $1.00(0.97-1.02 ; \mathrm{P}=0.71)$ \\
Male Gender & $1.41(0.44-4.51 ; \mathrm{P}=0.56)$ & $0.43(0.13-1.48 ; \mathrm{P}=0.18)$ \\
Non-Caucasian & $1.35(0.64-2.85 ; \mathrm{P}=0.43)$ & $1.13(0.56-2.30 ; \mathrm{P}=0.73)$ \\
Fasting Glucose & $1.04(1.04-1.05 ; \mathrm{P}=<0.001)$ & $1.04(1.03-1.05 ; \mathrm{P}=<0.001)$ \\
BMI & $1.06(1.03-1.09 ; \mathrm{P}=<0.001)$ & $0.99(0.96-1.03 ; \mathrm{P}=0.72)$ \\
Change in BMI & $0.73(0.69-0.78 ; \mathrm{P}=<0.001)$ & $0.76(0.70-0.83 ; \mathrm{P}=<0.001)$ \\
Sleep apnea ${ }^{*}$ & $1.53(1.21-1.94 \mathrm{P}=<0.001)$ & $1.43(1.10-1.86 ; \mathrm{P}=0.008)$ \\
\hline
\end{tabular}

See text for coding of variables.

$\mathrm{BMI}=$ body mass index $\mathrm{CI}=$ confidence interval

* Per Quartile of Sleep Apnea Severity 